\title{
Article \\ Specific Absolute Velocity Thresholds during Male Basketball Games Using Local Positional System; Differences between Age Categories
}

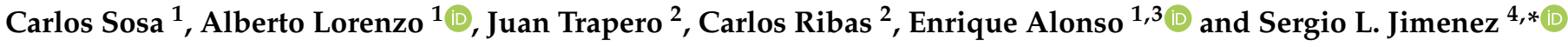 \\ 1 Facultad de Deportes, Universidad Politécnica de Madrid, 28040 Madrid, Spain; c_sosam@yahoo.es (C.S.); \\ alberto.lorenzo@upm.es (A.L.); ealonsoperezchao@gmail.com (E.A.) \\ 2 Faculty of Sport Sciences, European University of Madrid, 28670 Madrid, Spain; jthnut@yahoo.es (J.T.); \\ carlosribasaz@gmail.com (C.R.) \\ 3 Faculty of Sports Sciences, University Alfonso X the Wise, Villanueva de la Cañada, 28691 Madrid, Spain \\ 4 Centre for Sport Studies, Universidad Rey Juan Carlos, Fuenlabrada, 28943 Madrid, Spain \\ * Correspondence: sergio.jimenez.saiz@urjc.es
}

check for

updates

Citation: Sosa, C.; Lorenzo, A.; Trapero, J.; Ribas, C.; Alonso, E.; Jimenez, S.L. Specific Absolute Velocity Thresholds during Male Basketball Games Using Local Positional System; Differences between Age Categories. Appl. Sci. 2021, 11, 4390. https://doi.org/ 10.3390/app11104390

Academic Editor: Herbert Wagner

Received: 22 April 2021

Accepted: 10 May 2021

Published: 12 May 2021

Publisher's Note: MDPI stays neutral with regard to jurisdictional claims in published maps and institutional affiliations.

Copyright: (c) 2021 by the authors. Licensee MDPI, Basel, Switzerland. This article is an open access article distributed under the terms and conditions of the Creative Commons Attribution (CC BY) license (https:// creativecommons.org/licenses/by/ $4.0 /)$.

\begin{abstract}
The aim of this study was (I) to establish absolute specific velocity thresholds during basketball games using local positional system (LPS) and (II) to compare the speed profiles between various levels of competitions. The variables recorded were total distance (TD); meters per minute ( $\mathrm{m} \cdot \mathrm{min})$; real time $(\mathrm{min})$; maximum speed $\left(\mathrm{Km} \mathrm{h}^{-1}\right)$, distance $(\mathrm{m})$, percentage distance, and percentage duration invested in four speed zones (standing-walking; jogging; running; and high-speed running). Mean and standard deviation $( \pm S D)$ were calculated, and a separate one-way analysis of variance was undertaken to identify differences between competitions. TD (3188.84 $\pm 808.37 \mathrm{~m})$ is covered by standing-walking (43.51\%), jogging (36.58\%), running $(14.68 \%)$, and sprinting $(5.23 \%)$ activities. Overall, $75.22 \%$ of the time is invested standing-walking, jogging (18.43\%), running (4.77\%), and sprinting (1.89\%). M-min (large effect size), \% duration zone 2 (moderate effect size); distance zone 4 (large effect size), and \% distance zone 4 (very large effect size) are significantly higher during junior than senior. However, \% distance zone 1 (large effect size) and \% duration zone 1 (large effect size) were largely higher during senior competition. The findings of this study reveal that most of the distance and play time is spent during walking and standing activities. In addition, the proportion of time spent at elevated intensities is higher during junior than in senior competition.
\end{abstract}

Keywords: global positional system; physical performance; team sports; ultra-wide band; physical demands; load monitoring; on-court performance

\section{Introduction}

Basketball is an intermittent, dynamic, and complex team sport where the majority of play time is dedicated to walking and standing activities [1]. During games, periods of low to moderate intensity are interchanged with high intensity moments [2], where continuous changes of direction, jumps, sprints, accelerations, decelerations, contacts, and specific skills are mainly presented [3-6].

For better understanding of the movement patterns and external loads charged on players, many studies that were applied in a wide variety of sample (i.e., male/female, junior/senior), have analyzed distances covered and specific movements in different velocity thresholds $[4,6-9]$. In a previous study carried out with U18 basketball players, match activity has been classified into the following categories: stationary/walking $\left(<6.0 \mathrm{Km} \mathrm{h}^{-1}\right)$, jogging $\left(6.0-12.0 \mathrm{Km} \mathrm{h}^{-1}\right)$, running (12.1-18.0 $\left.\mathrm{Km} \mathrm{h}^{-1}\right)$, high-intensity running (18.1-24.0 $\left.\mathrm{Km} \mathrm{h}^{-1}\right)$, and sprinting $\left(>24.1 \mathrm{Km} \mathrm{h}^{-1}\right)$ [10]. The percentage of distance covered at each specific speed threshold is established as standing/walking: 23.4-66.3\%; jogging: 5.6-36.3\%; running: $4.5-33.2 \%$; and sprinting: $0.3-8.5 \%[3,5,6,11]$. These ranges 
of values mainly differ due to the lack of specificity and individualization as well as the different methodologies used in the studies.

The mean distance in most studies across 40 min matches ranges from 4404 to $7558 \mathrm{~m}$ [4]. Nevertheless, this wide and inconsistent range is due to several methodological and external factors such as instrument used to measure, playing position, gender, competition level, age category, excluding match stoppages ( $5215 \pm 314 \mathrm{~m})$, including match stoppages $(7039 \pm 446 \mathrm{~m})$, taking into consideration or excluding warm ups, etc. $[4,12,13]$. Differences in basketball game demands, depending on the age or competition level, have been observed [7], allowing coaches to modify and prepare players according to the competition level. Previous research suggests differences between competitions (senior vs. junior), reporting that senior leagues (over eighteen years) tend to have a lower intensity and higher volume resulting in a more tactical game play $[14,15]$. Samples should be individualized and specified according to the previous factors mentioned in order to gain a better understanding of the data collection.

The first method put into practice for the analysis of the movement of time in basketball was the cartographic technique, which is currently outdated, due to technology advancing exponentially [9]. Since then, many studies have quantified the activity demands during basketball games, predominantly using time-motion analysis (TMA) [4-6]. However, registering location information within indoor sports requires higher precision and is a more challenging task (e.g., more expensive or higher access difficulty if appears a facility alternation during games and practices) than outdoor environments [16]. There are emerging novel instruments, such as positional systems (wearable sensors) that transmit information through different ways (e.g., ultrasound, radiofrequency, ultra-wide band (UWB). In turn, these wearable sensors using UWB provide valuable individualized information used to manage the workload during training sessions and games $[13,17]$. In addition, this technology has been proven to be a valid and reliable equipment for analyzing position, speed, and distance in indoor sports [18-20].

There are several advantages of using this technology. These include the capability to monitor several players at once, the time effectiveness of the analysis, and the ability to receive information in real time [21]. Furthermore, other studies have shown that moderate correlations exist between distance load variables and internal load parameters such as Rate of Perceived Exertion [22]. Due to the fact that positional methods are an expensive and recent technology, few studies have analyzed distances covered and specific velocity thresholds using indoor positioning systems $[8,23]$. However, these studies evaluate it during 20-min simulated games [8] and female matches [8]. In turn, these studies differ to each other at the time to specify velocity thresholds, as some consider $>24 \mathrm{~km} \cdot \mathrm{h}^{-1}$ as a sprinting action [8] and others $>14 \mathrm{Km} \mathrm{h}^{-1}$ [8]. These differences can be a result of gender differences or not considering the dimensions of a basketball court, which could prevent athletes from reaching a sprint speed $>24 \mathrm{Km} \mathrm{h}^{-1}$, and if the athletes do reach that speed, it would be during an insignificant range of time [8]. However, there is some confusion and inconsistency when determining velocity thresholds [24], extending this debate to the duration of the actions. Previous research from field sports stipulates that in order to consider an action as a sprint, this has to occur in a period over one second [25-27], while other studies do not state the duration for a sprint to occur [28,29]. In addition, there exists a lack of absolute thresholds derived from the local positioning system (LPS) due to the fact that this technology is usually allocated in different installations where the games are played or the devices are not allowed by federations and institutions during official games. In addition, knowing the specific velocity thresholds would permit the development of more precise conditioning programs for basketball players. Consequently, further research is needed to clarify the prior features mentioned.

For these reasons, the aim of this study was (I) to establish absolute specific velocity thresholds during basketball games using LPS, for the same team during one competitive season, and (II) to compare the activity and speed profiles between various levels of competitions within the same team throughout the same season. 


\section{Materials and Methods}

\subsection{Sample}

Data were collected from 10 elite, junior male players [30] (age $16.92 \pm 1.05$ years, height $197.53 \pm 8.74 \mathrm{~cm}$, body mass $87.36 \pm 8.11 \mathrm{~kg}$ ). The same team was competing in two different leagues playing twice per week. Thus, eighteen official games within two different competitions (I) under-eighteen (U18) regional league (Junior) $n=9$; (II) amateur Spanish fourth national basketball division (Senior), $n=9$ were collected throughout the season 2019-2020 (from October to March). Overall, 117 game samples across the 10 players were included in the analysis.

The exclusion criteria followed throughout the study was a minimum of twenty minutes of real time on court per match, where all players from the team that had less than twenty minutes of real time on the court per match were excluded from that game but not from the study. All participants had to perform at least $30 \%$ of the matches at each competition. Furthermore, the data collected at the pre-game warm up, rest periods between quarters, and time-outs had not been taken into consideration. The subjects were informed about the purpose, risks, and benefits of the study and they gave their informed consent in accordance with the Declaration of Helsinki [31].

\subsection{Procedures}

This observational study was conducted during twenty games of the 2019-2020 competitive basketball season. Each player wore a device (ClearSky S7, Catapult Sports, Melbourne, Australia) in a bespoke pocket fitted under their jersey (on the upper thoracic spine between the scapula), which a previous study has suggested to be an accurate location [32]. All participants were familiar with the device, as they have been using this technology on each training session and game of the previous season prior to when the study data collection started.

Each LPS unit captures data at a sample of $10 \mathrm{~Hz}$. The ClearSky LPS system (Catapult ClearSky, Catapult Sports, Melbourne, Australia) is an UWB, $4 \mathrm{GHz}$ transmitting system and is equipped with 24 anchors in the perimeter of the training hall. The antennae continually send information to LPS receivers carried by the players (device). This technology revealed a mean error below $5 \%$ measuring distances and average speeds. [33]. In turn, it has been proven to show an acceptable level of accuracy and reliability in determining the position and estimating distances and speeds for measuring the high-intensity distance covered in multi-directional sports such as basketball $[16,19,20,34-40]$. In turn, this system has been developed and validated against factors that might affect signal quality such as devices connected to local Wi-Fi networks, physical obstacles such as court-dividing curtains or other Bluetooth-enabled devices $[18,19,38]$. Units were turned on prior to each game $(\approx 20-40$ min before starting the warm up), and players wore the same device throughout the study period to avoid inter-unit variation players [34,41,42].

Catapult sports devices recorded the parameters required for the study and uploaded them to their own software Openfield cloud (version 2.4.0). Once the required parameters for the study were selected, the data were exported to Microsoft Excel (version 16.0, Microsoft Corporation, Redmond, WA, USA) to apply the exclusion criteria previously specified.

\subsection{Variables}

The parameters recorded were total distance $(\mathrm{m})$; meters per minute $(\mathrm{m} \cdot \mathrm{min})$; real time (min); maximum speed $\left(\mathrm{Km} \mathrm{h}^{-1}\right)$ reached by a player during the game and distance (m), percentage distance and percentage duration invested in four speed zones (standingwalking; jogging; running; and high-speed running).

Total distance (TD) is meters covered by the players while on the field; $\mathrm{m} \cdot \mathrm{min}^{-1}$ is the distance in meters covered relativized in a minute. Real time (RT) is the time in minutes that each player invests on the court during the match, including when the ball is stopped (that is: free throws, when the referee is marking a fault, or during players' changes). Distance $(\mathrm{m})$ is the meters covered in each speed zone, \% duration is the percentage of 
time in minutes invested in each different speed zone, while \% distance is the percentage of distance in meters invested on each different speed zone. Distance, $\%$ duration, and $\%$ distance were classified into the following four absolute velocity thresholds similar to a previous study [23] (Table 1). However, this study does not refer to sprint running as distance covered over $24 \mathrm{Km} \mathrm{h}^{-1}$. This threshold has not been considered as a sprint because basketball players usually do not achieve that speed [23]. Moreover, $24 \mathrm{Km} \mathrm{h}^{-1}$ is not yet a sprint as a sprint is a maximum speed, and the dimensions of a basketball court are not big enough for the players to reach maximum speeds [23].

Table 1. Absolute velocity thresholds.

\begin{tabular}{cc}
\hline Speed Zones & Speed \\
\hline Zone 1 (Standing-Walking) & $<7 \mathrm{Km} \mathrm{h}^{-1}$ \\
Zone 2 (Jogging) & $7-14 \mathrm{Km} \mathrm{h}^{-1}$ \\
Zone 3 (Running) & $>14-18 \mathrm{Km} \mathrm{h}^{-1}$ \\
Zone 4 (High Speed Running) & $>18.0 \mathrm{Km} \mathrm{h}^{-1}$ \\
\hline
\end{tabular}

Classification of absolute velocity thresholds based on previous similar study [23].

\subsection{Statistical Analysis}

Mean \pm standard deviation (SD) and coefficient of variation (CV\%) were calculated for all TMA variables. The normality of data distribution and sphericity were confirmed using the Shapiro-Wilk test. The adjustment for multiple comparisons was performed using Bonferroni, and the mean difference is considered significant at $p<0.05$. To identify differences between competitions, a separate one-way analysis of variance (ANOVA) was undertaken. Effect size (ES) for competition comparisons was determined using Cohen's $\mathrm{d}$ and was interpreted as follows: trivial $=0$ to 0.19 , small $=0.2$ to 0.59 , moderate $=0.6$ to 1.19 , large $=1.2$ to 1.99 , very large $=2.0$ to 3.99 , and nearly perfect $\geq 4.0$ [43]. Descriptive analysis and ANOVA were conducted using the statistical software JASP (Version 0.12.2), while ES were calculated using a customized Microsoft Excel spreadsheet.

\section{Results}

The descriptive analysis of parameters during the full game and specific velocity thresholds is presented in Table 2. The percentage distance covered, and duration percentage invested in different velocity thresholds are displayed respectively in Figures 1 and 2. ES for all comparisons between senior and junior (Table 3) show that $\mathrm{m} \cdot \mathrm{min}(p<0.001$, large effect size); \% duration zone $2(p<0.001$, moderate effect size); distance zone 4 $(p<0.001$, large effect size); and \% distance zone $4(p<0.001$, very large effect size) are significantly higher during the junior competition than in senior games. Nevertheless, $\%$ distance zone 1 ( $p<0.001$, large effect size) and \% duration zone $1(p<0.001$, large effect size) were largely higher during senior competition. 
Table 2. Descriptive analysis of all variables.

\begin{tabular}{|c|c|c|c|c|c|c|}
\hline Zone & Variables & $\mathbf{N}$ & Mean & SD & $\mathrm{CV} \%$ & Shapiro-Wilk \\
\hline \multirow{4}{*}{ Full Game } & Total Distance (m) & 117 & 3188.84 & 808.37 & $25 \%$ & $p=0.055$ \\
\hline & $\mathrm{m} \cdot \mathrm{min}$ & 117 & 83.95 & 7.24 & $8 \%$ & $p=0.181$ \\
\hline & Real Time (min, seg) & 117 & 38.02 & 10.00 & $26 \%$ & $p=0.036$ \\
\hline & Maximum Velocity $\left(\mathrm{Km} \mathrm{h}^{-1}\right)$ & 117 & 24.54 & 1.72 & $7 \%$ & $p<0.001$ \\
\hline \multirow{3}{*}{$\begin{array}{c}\text { Zone } 1 \\
\left(0-7.00 \mathrm{Km} \mathrm{h}^{-1}\right)\end{array}$} & Distance $(\mathrm{m})$ & 117 & 1364.57 & 376.84 & $27 \%$ & $p=0.024$ \\
\hline & \% Distance & 117 & 43.51 & 3.84 & $8 \%$ & $p=0.334$ \\
\hline & $\%$ Duration & 117 & 75.22 & 3.00 & $3 \%$ & $p=0.359$ \\
\hline \multirow{3}{*}{$\begin{array}{c}\text { Zone } 2 \\
\left(7.01-14 \mathrm{Km} \mathrm{h}^{-1}\right)\end{array}$} & Distance (m) & 117 & 1163.80 & 302.32 & $25 \%$ & $p=0.173$ \\
\hline & \% Distance & 117 & 36.58 & 3.59 & $9 \%$ & $p=0.086$ \\
\hline & \% Duration & 117 & 18.43 & 2.48 & $13 \%$ & $p=0.213$ \\
\hline \multirow{3}{*}{$\begin{array}{c}\text { Zone } 3 \\
\left(14.01-18 \mathrm{Km} \mathrm{h}^{-1}\right)\end{array}$} & Distance (m) & 117 & 469.07 & 144.99 & $30 \%$ & $p=0.096$ \\
\hline & \% Distance & 117 & 14.68 & 2.53 & $17 \%$ & $p=0.225$ \\
\hline & $\%$ Duration & 117 & 4.77 & 1.04 & $21 \%$ & $p=0.003$ \\
\hline \multirow{3}{*}{$\begin{array}{c}\text { Zone } 4 \\
\left(>18.01 \mathrm{Km} \mathrm{h}^{-1}\right)\end{array}$} & Distance (m) & 117 & 165.43 & 73.64 & $44 \%$ & $p=0.010$ \\
\hline & \% Distance & 117 & 5.23 & 2.16 & $41 \%$ & $p<0.001$ \\
\hline & $\%$ Duration & 117 & 1.89 & 1.19 & $62 \%$ & $p<0.001$ \\
\hline
\end{tabular}

$\mathrm{N}$ represent game samples across the 10 players monitored. Abbreviations: $\mathrm{CV} \%=$ The coefficient of variation in percentage.

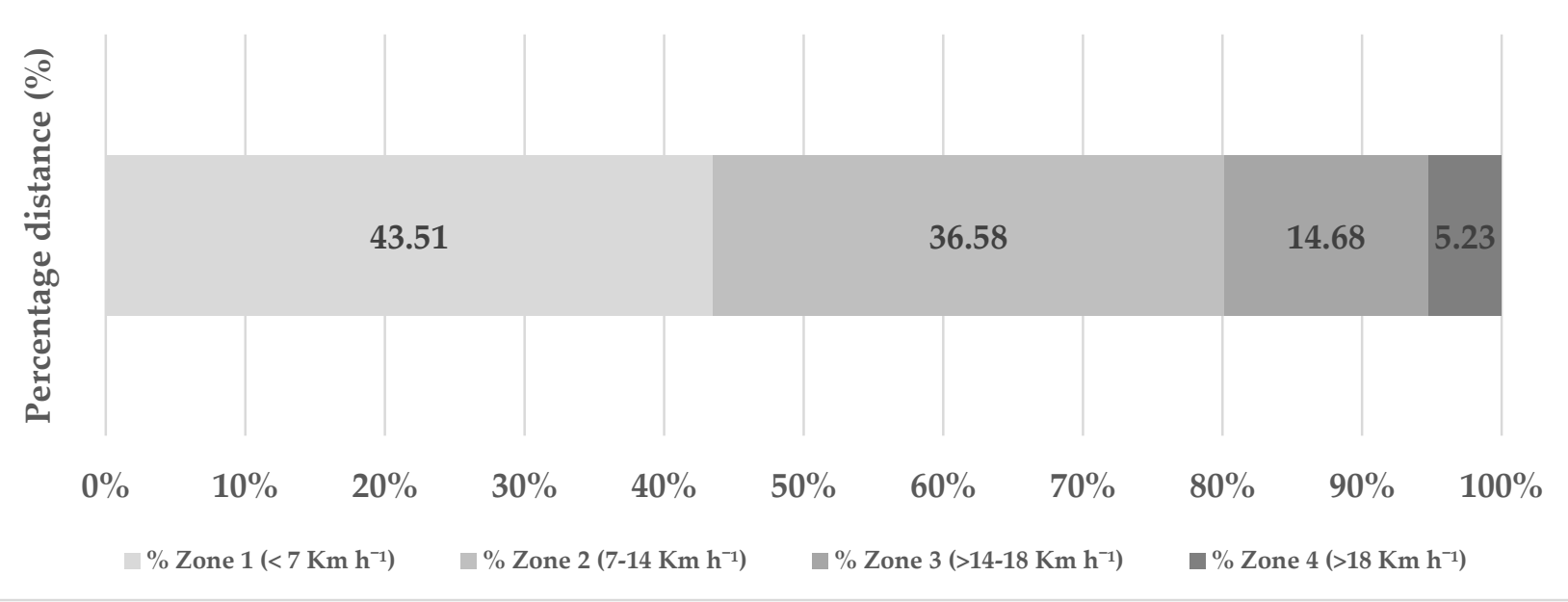

Figure 1. Descriptive analysis of percentage distance (\% meters) invested in each specific velocity threshold.

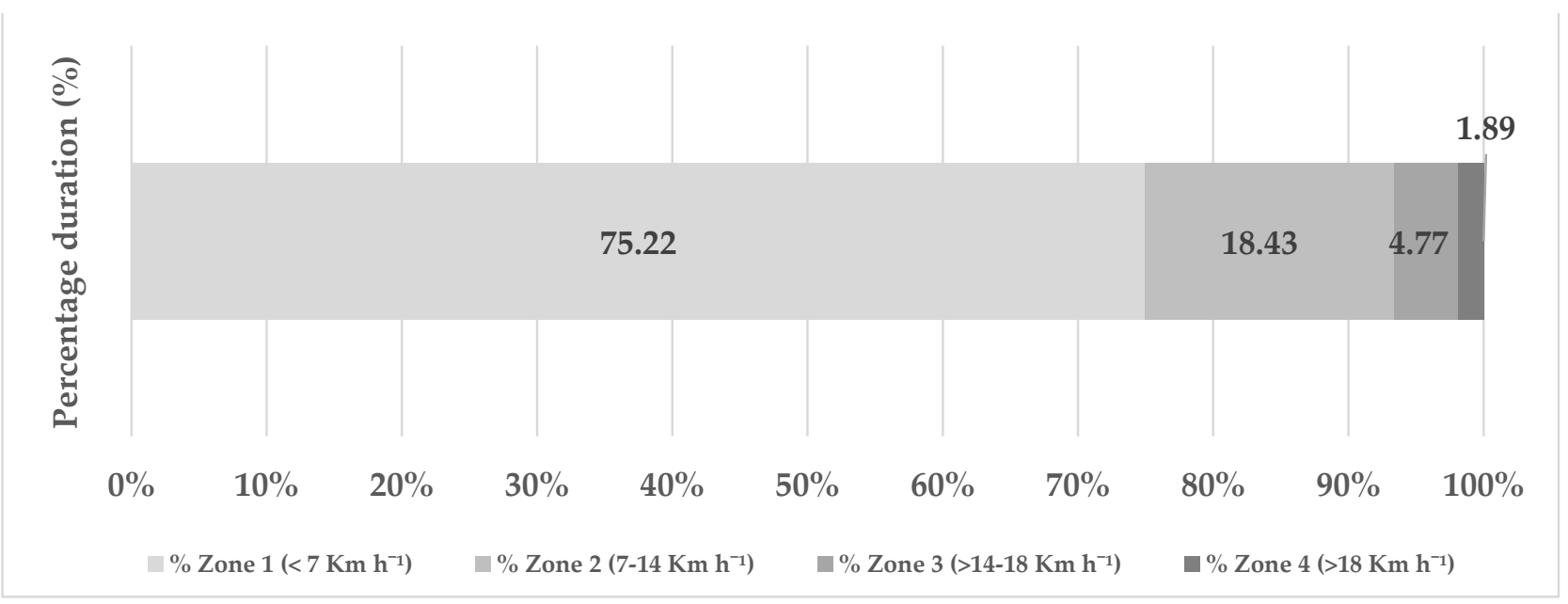

Figure 2. Descriptive analysis of percentage duration (\% min) invested in each specific velocity threshold. 
Table 3. Descriptive analysis (mean \pm SD) and differences between competitions.

\begin{tabular}{|c|c|c|c|c|c|c|c|c|c|}
\hline & \multirow{2}{*}{ Parameter } & \multicolumn{2}{|c|}{ Senior } & \multicolumn{2}{|c|}{ Junior } & \multirow{2}{*}{$\mathbf{F}$} & \multirow{2}{*}{ P Tukey } & \multirow{2}{*}{ Effect Size } & \multirow{2}{*}{$\begin{array}{l}\text { Effect Size } \\
\text { Magnitude }\end{array}$} \\
\hline & & Mean & SD & Mean & SD & & & & \\
\hline \multirow{4}{*}{ Full Game } & Total Distance (m) & 3325.14 & \pm 899.84 & 3029.82 & \pm 659.639 & 3.98 & 0.048 & 0.37 & Small \\
\hline & $\mathrm{m} \cdot \mathrm{min}$ & 81.65 & \pm 7.037 & 86.64 & \pm 6.574 & 15.55 & 0.001 & -0.73 & Moderate \\
\hline & Real Time (min, seg) & 40.67 & \pm 10.96 & 34.93 & \pm 7.761 & 10.35 & 0.002 & 0.59 & Small \\
\hline & Max Velocity $\left(\mathrm{Km} \mathrm{h}^{-1}\right)$ & 24.41 & \pm 1.34 & 24.59 & \pm 1.698 & 0.39 & 0.533 & -0.11 & Trivial \\
\hline \multirow{3}{*}{$\begin{array}{c}\text { Zone } 1 \\
\left(0-7.00 \mathrm{Km} \mathrm{h}^{-1}\right)\end{array}$} & Distance (m) & 1455.04 & \pm 415.49 & 1259.02 & \pm 296.261 & 8.37 & 0.005 & 0.53 & Small \\
\hline & $\%$ Distance & 45.20 & \pm 3.19 & 41.54 & \pm 3.593 & 34.11 & 0.001 & 1.08 & Moderate \\
\hline & $\%$ Duration & 76.24 & \pm 2.69 & 74.02 & \pm 2.922 & 18.22 & 0.001 & 0.79 & Moderate \\
\hline \multirow{3}{*}{$\begin{array}{c}\text { Zone } 2 \\
\left(7.01-14 \mathrm{Km} \mathrm{h}^{-1}\right)\end{array}$} & Distance (m) & 1199.01 & \pm 3.37 & 1122.72 & \pm 3.741 & 1.87 & 0.175 & 0.25 & Small \\
\hline & \% Distance & 342.40 & \pm 17.67 & 244.33 & \pm 19.3 & 3.59 & 0.061 & -0.35 & Small \\
\hline & $\%$ Duration & 36.01 & \pm 2.26 & 37.25 & \pm 2.462 & 13.79 & 0.001 & -0.68 & Moderate \\
\hline \multirow{3}{*}{$\begin{array}{c}\text { Zone 3 } \\
\left(14.01-18 \mathrm{Km} \mathrm{h}^{-1}\right)\end{array}$} & Distance (m) & 483.89 & \pm 2.51 & 451.78 & \pm 2.571 & 1.43 & 0.234 & 0.22 & Small \\
\hline & \% Distance & 152.16 & \pm 4.59 & 135.50 & \pm 4.968 & 0.23 & 0.627 & -0.09 & Trivial \\
\hline & $\%$ Duration & 14.58 & \pm 0.97 & 14.81 & \pm 1.081 & 3.76 & 0.055 & -0.35 & Small \\
\hline \multirow{3}{*}{$\begin{array}{c}\text { Zone } 4 \\
\left(>18.01 \mathrm{Km} \mathrm{h}^{-1}\right)\end{array}$} & Distance (m) & 139.83 & \pm 1.57 & 195.29 & \pm 2.152 & 19.06 & 0.001 & -0.81 & Moderate \\
\hline & $\%$ Distance & 58.90 & \pm 2.07 & 78.25 & \pm 1.676 & 40.02 & 0.001 & -1.17 & Moderate \\
\hline & $\%$ Duration & 4.22 & \pm 1.50 & 6.40 & \pm 0.602 & 3.36 & 0.069 & -0.73 & Moderate \\
\hline
\end{tabular}

\section{Discussion}

The aim of the study was to establish absolute specific velocity thresholds during basketball games using LPS. This paper also aimed to compare the intensity thresholds between junior and senior competition, within the same team and throughout the same season. As of now, very few papers have analyzed specific velocity thresholds in basketball using positional systems $[8,10]$ due to monitor location parameters in indoor sports requiring higher precision, which proves to be a more challenging task than in outdoor environments [16]. This study offers novel information that should be considered by basketball practitioners. Additionally, the findings of this research provide a better understanding of (I) distances covered, (II) specific thresholds, and (III) differences between competitions among basketball players.

\subsection{Distances Covered}

Results showed that TD ( $3188.84 \pm 808.37 \mathrm{~m})$ is less than distances covered reported by previous studies that applied TMA (from 4404 to $7558 \mathrm{~m}$ ) [4,5]. The results are slightly lower to a study to that applied UWB technology, where distances reported were from 2000 to $4000 \mathrm{~m}$ [8]. Although, it is important to take into consideration that the devices the manufacturer used and the gender were different. As we know, TD will be determined by contextual factors during the game (such as quality rival, competition, tactical aspects, etc.), methodological factors, technology applied, and mainly, the duration that each player is on the court [44,45]. If we compare $\mathrm{m} \cdot \mathrm{min}(83.95 \pm 7.24 \mathrm{~m})$ with previous studies that have used LPS [8,45], the outcomes gave contradictory results. This could be due to differences in sample and methodology factors such as gender, age category, level competition, and technology applied. Consequently, these are difficult to discuss. In turn, these results should be considered by physical trainers and basketball coaches in order to prepare specific exercises during training sessions.

\subsection{Specific Thresholds}

The results show that the majority of the distance $(80 \%)$ is covered standing-walking $(43.51 \%)$ and jogging $(36.58 \%)$. The remaining $20 \%$ of distance is performed running $(14.68 \%)$, and only $5.23 \%$ is spent sprinting. From a duration perspective, $93.67 \%$ of the time is invested standing-walking $(75.22 \%)$ and jogging $(18.43 \%)$. During the remaining $6.66 \%$ of play time, athletes are running $(4.77 \%)$ or covering distance over $18 \mathrm{Km} \mathrm{h}^{-1}(1.89 \%)$.

Due to differences in velocity intensity thresholds, the technology applied (time motion analysis, LPS), the manufacturer devices used (e.g., WIMU, Catapult Sports), the confusion and inconsistency when determining velocity thresholds and sample character- 
istics (age, level, gender, etc.), it is difficult to compare results with previous papers that analyze distance thresholds during basketball games $[6-8,10]$. These studies provide a clear understanding about external load and basketball intensity thresholds. As previous findings confirmed, basketball is a sport where most of play time is spent in walking and standing activities $[1,5,8]$. However, the capacity to be exposed to accelerations, decelerations, change of directions, landings, peak demands, or jumps is vital for on-court success, due to the intermittent high-intensity nature of most actions and basketball specific movements [1,46-51].

In addition, the aim of the study was to establish absolute specific velocity thresholds during basketball games. The results show that a low variability in max velocity $\left(24.54 \pm 1.72 \mathrm{Km} \mathrm{h}^{-1}\right)$ is sustained due to the fact that the basketball court size $(28 \times 15 \mathrm{~m})$ did not allow players to achieve more maximum velocities. Thus, we do not consider a sprint to occur at a speed $>24 \mathrm{Km} \mathrm{h}^{-1}$, because in basketball, the dimensions of the court are smaller than other team field-based sports, limiting the sprint action. Previous findings revealed that a very low proportion of movements are performed over $24 \mathrm{Km} \mathrm{h}^{-1}$ $(0.2 \pm 0.7 \mathrm{~m} \cdot \mathrm{min})$ during basketball games [23]. Therefore, during this study, we do not consider sprint as a velocity threshold with our argument being that if the athlete reaches a speed $>18 \mathrm{Km} \mathrm{h}^{-1}$, they would still be accelerating, and if the player reaches a speed $>24 \mathrm{Km} \mathrm{h}^{-1}$, it would be during an insignificant period of time [23]. It is likely that distance performed over $24 \mathrm{Km} \mathrm{h}^{-1}$ might represent an irrelevant advantage for success in basketball.

Additionally, the low variability in max velocity $(\mathrm{CV} \%=7)$ could indicate that the use of individualized thresholds does not make a lot of sense in sports where lower variability in maximum velocities is given. The use of absolute and relative threshold, being maximum velocity similar between players, would only provide two different perspectives to understand velocity thresholds (e.g., the player covers $1300 \mathrm{~m}$ in zone 1 or $1300 \mathrm{~m}$ at the $\mathrm{x} \%$ of his maximum velocity). This would limit, but not eliminate, the use of maximal velocity when determining a sprint threshold [52].

Differences in performance capacities across age and gender groups are important factors when deciding on intensity thresholds due to physical differences (e.g., athletes' biological maturity or rate of force development) [53]. For better understanding of absolute and relative intensity thresholds, researchers and practitioners need to mutually decide upon the best velocity for each absolute threshold and percentage ranges for relative locomotor thresholds.

Despite those factors, basketball practitioners should determinate a criterion and should be consistent with their choice. Furthermore, researchers should include detailed information in research publications.

\subsection{Differences between Competitions}

ES (Cohen's d) for all comparisons indicated that meters per minute were moderately higher ( $p<0.001$, large effect) during junior games than in the senior category. This could be principally related to the game pace and technical-tactical factors. Additionally, some studies reported more $\mathrm{m} \cdot \mathrm{min}-1$ during youth basketball games than senior matches [15].

Another finding was that $\%$ distance $(p<0.001$, large effect) and \% duration $(p<0.001$, large effect) spent over $18 \mathrm{Km} \mathrm{h}^{-1}$ were significantly higher during junior competition than senior. However, \% distance ( $p<0.001$, large effect) and \% duration $(p<0.001$, large effect) spent on standing-walking activities $\left(<7 \mathrm{Km} \mathrm{h}^{-1}\right)$ were largely higher during senior games.

These results are similar to a previous study carried out in different Italian competitive levels (e.g., Division I, Division II, and Division III) that suggest junior teams normally perform for a longer time at their high and moderate intensity periods, while senior teams lean toward a longer recovery period [14]. The reason for this could be that younger players make worse decisions when running than experienced basketball players; in addition, senior leagues tend to be more tactical than junior leagues $[14,15]$. 
Furthermore, fast-break situations tend to be more often in youth games. In addition, the format of the game and the major inclusion of time-outs, free throws, and the high number of faults during senior games play an important role allowing longer periods of recovery. The previous factors mentioned are resulting in an increment of the time spent on standing-walking activities [51].

\section{Limitations of the Study}

Although this study was applied to a small number of limitations, there are some important aspects that should be taken into consideration.

Firstly, the results are indicative of the specific team context analyzed and may not be representative of teams of different ages, playing levels, and gender. On the other hand, to know the specific context for the same team during one competitive season provides high value due to most studies being based on the data from different teams and isolated games.

In addition, data were collected under similar conditions throughout the games; however, variables such as score, playing positions, role player, rival's quality, tactical aspects, or other factors that could have directly or indirectly influenced the study results were not controlled.

\section{Conclusions}

The present study has established the activity and speed profiles using LPS. Findings of this research provide a better understanding of distances covered, specific thresholds, and differences between competitions during male basketball games.

Most of distance and play time is spent in walking and standing activities; however, distance performed over $24 \mathrm{Km} \mathrm{h}^{-1}$ might represent an insignificant advantage for success in basketball. Nevertheless, the capacity to accelerate, decelerate, change direction, or jump is vital for performance due to the intermittent high-intensity and basketball-specific nature of most actions.

Percentage distance and duration spent on standing-walking activities is higher during senior than junior games, while the proportion of time spent at elevated intensities is higher during junior than senior competition. These findings should be considered by basketball practitioners in order to prepare specific exercises during training sessions.

Author Contributions: Conceptualization, E.A. and C.S.; methodology, E.A. and S.L.J.; software, E.A., C.S. and J.T.; validation, E.A., C.S. and J.T.; formal analysis, C.R. and E.A.; investigation, E.A. and C.S.; resources, C.S. and J.T.; data curation, E.A., A.L. and S.L.J.; writing-original draft preparation, C.R., E.A. and C.S.; writing-review and editing, E.A., C.S. and A.L.; visualization, E.A.; supervision, S.L.J. and A.L.; project administration, E.A., S.L.J. and A.L.; funding acquisition, S.L.J. All authors have read and agreed to the published version of the manuscript.

Funding: The APC was funded by Universidad Rey Juan Carlos.

Institutional Review Board Statement: Not applicable.

Informed Consent Statement: Not applicable.

Conflicts of Interest: The authors declare no conflict of interest.

\section{References}

1. Narazaki, K.; Berg, K.; Stergiou, N.; Chen, B. Physiological demands of competitive basketball. Scand. J. Med. Sci. Sports 2009, 19, 425-432. [CrossRef] [PubMed]

2. Abdelkrim, N.B.; El Fazaa, S.; El Ati, J. Time-motion analysis and physiological data of elite under-19-year-old basketball players during competition. Br. J. Sports Med. 2007, 41, 69-75. [CrossRef] [PubMed]

3. Delextrat, A.; Badiella, A.; Saavedra, V.; Matthew, D.; Schelling, X.; Torres-Ronda, L. Match activity demands of elite Spanish female basketball players by playing position. Int. J. Perform. Anal. Sport 2015, 15, 687-703. [CrossRef]

4. Stojanović, E.; Stojiljković, N.; Scanlan, A.T.; Dalbo, V.J.; Berkelmans, D.M.; Milanović, Z. The activity demands and physiological responses encountered during basketball match-play: A systematic review. Sports Med. 2018, 48, 111-135. [CrossRef]

5. Scanlan, A.T.; Dascombe, B.J.; Reaburn, P.; Dalbo, V.J. The physiological and activity demands experienced by Australian female basketball players during competition. J. Sci. Med. Sport 2012, 15, 341-347. [CrossRef] 
6. Matthew, D.; Delextrat, A. Heart rate, blood lactate concentration, and time-motion analysis of female basketball players during competition. J. Sports Sci. 2009, 27, 813-821. [CrossRef]

7. Abdelkrim, N.B.; Castagna, C.; Jabri, I.; Battikh, T.; El Fazaa, S.; El Ati, J. Activity profile and physiological requirements of junior elite basketball players in relation to aerobic-anaerobic fitness. J. Strength Cond. Res. 2010, 24, 2330-2342. [CrossRef]

8. Reina, M.; García-Rubio, J.; Ibáñez, S.J. Activity Demands and Speed Profile of Young Female Basketball Players Using Ultra-Wide Band Technology. Int. J. Environ. Res. Public Health 2020, 17, 1477. [CrossRef]

9. Hulka, K.; Cuberek, R.; Svoboda, Z. Time-motion analysis of basketball players: A reliability assessment of Video Manual Motion Tracker 1.0 software. J. Sports Sci. 2013, 32, 53-59. [CrossRef]

10. Vázquez-Guerrero, J.; Fernández-Valdés, B.; Jones, B.; Moras, G.; Reche, X.; Sampaio, J. Changes in physical demands between game quarters of U18 elite official basketball games. PLoS ONE 2019, 14, e0221818. [CrossRef]

11. Scanlan, A.T.; Tucker, P.S.; Dascombe, B.J.; Berkelmans, D.M.; Hiskens, M.I.; Dalbo, V.J. Fluctuations in activity demands across game quarters in proffesional and semiprofessional male basketball. J. Strength Cond. Res. 2015, 29, 3006-3015. [CrossRef]

12. Portes, R.; Navarro, R.M.; Sosa, C.; Trapero, J.J.; Jiménez, S.L. Monitoring and interpreting external load in basketball: A narrative review. Rev Psicol del Deport. 2019, 28, 119-131.

13. Varley, M.C.; Jaspers, A.; Helsen, W.F.; Malone, J.J. Methodological Considerations When Quantifying High-Intensity Efforts in Team Sport Using Global Positioning System Technology. Int. J. Sports Physiol. Perform. 2017, 12, 1059-1068. [CrossRef]

14. Ferioli, D.; Schelling, X.; Bosio, A.; La Torre, A.; Rucco, D.; Rampinini, E. Match Activities in Basketball Games: Comparison Between Different Competitive Levels. J. Strength Cond. Res. 2020, 34, 172-182. [CrossRef]

15. Garcia, F.; Reche, X. Carga Externa en Baloncesto Formativo y Profesional Durante Competición Oficial. Poster Presented at ASEPREB Congress 2019, Barcelona. Available online: https://www.researchgate.net/profile/Franc-Garcia/publication/3341 39194_CARGA_EXTERNA_EN_BALONCESTO_FORMATIVO_Y_PROFESIONAL_DURANTE_COMPETICION_OFICIAL/ links/5d1a19a6299bf1547c8df7d1/CARGA-EXTERNA-EN-BALONCESTO-FORMATIVO-Y-PROFESIONAL-DURANTECOMPETICION-OFICIAL.pdf (accessed on 6 May 2021).

16. Hodder, R.W.; Ball, K.A.; Serpiello, F.R. Criterion Validity of Catapult ClearSky T6 Local Positioning System for Measuring Inter-Unit Distance. Sensors 2020, 20, 3693. [CrossRef]

17. Cummins, C.; Orr, R.; O'Connor, H. Global positioning systems (GPS) and microtechnology sensors in team sports: A systematic review. Sport Med. 2013, 43, 1025-1042. [CrossRef]

18. Luteberget, L.S.; Spencer, M.; Gilgien, M. Validity of the Catapult ClearSky T6 Local Positioning System for Team Sports Specific Drills, in Indoor Conditions. Front. Physiol. 2018, 9, 115. [CrossRef]

19. Serpiello, F.R.; Hopkins, W.G.; Barnes, S.; Tavrou, J.; Duthie, G.M.; Aughey, R.J.; Ball, K. Validity of an ultra-wideband local positioning system to measure locomotion in indoor sports. J. Sports Sci. 2018, 36, 1727-1733. [CrossRef] [PubMed]

20. Jennings, D.; Cormack, S.; Coutts, A.J.; Boyd, L.; Aughey, R.J. The validity and reliability of GPS units for measuring distance in team sport specific running patterns. Int. J. Sports Physiol. Perform. 2010, 5, 328-341. [CrossRef]

21. Aughey, R.J.; Falloon, C. Real-time versus post-game GPS data in team sports. J. Sci. Med. Sport 2010, 13, 348-349. [CrossRef]

22. Bartlett, J.D.; O'Connor, F.; Pitchford, N.; Torres-Ronda, L.; Robertson, S.J. Relationships between internal and external training load in team-sport athletes: Evidence for an individualized approach. Int. J. Sports Physiol. Perform. 2017, 12, 230-234. [CrossRef] [PubMed]

23. Puente, C.; Abián-Vicén, J.; Areces, F.; López, R.; Del Coso, J. Physical and physiological demands of experienced male basketball players during a competitive game. J. Strength Cond. Res. 2017, 31, 956-962. [CrossRef] [PubMed]

24. Sweeting, A.J.; Cormack, S.J.; Morgan, S.; Aughey, R.J. When is a sprint a sprint? A review of the analysis of team-sport athlete activity profile. Front. Physiol. 2017, 8, 432. [CrossRef] [PubMed]

25. Clarke, A.C.; Anson, J.; Pyne, D. Physiologically based GPS speed zones for evaluating running demands in Women's Rugby Sevens. J. Sports Sci. 2015, 33, 1101-1108. [CrossRef]

26. Vescovi, J.D. Impact of maximum speed on sprint performance during high-level youth female field hockey matches: Female Athletes in Motion (FAiM) study. Int. J. Sports Physiol. Perform. 2014, 9, 621-626. [CrossRef]

27. Carling, C.; Le Gall, F.; Dupont, G. Analysis of repeated high-intensity running performance in professional soccer. J. Sports Sci. 2012, 30, 325-336. [CrossRef]

28. Kempton, T.; Sullivan, C.; Bilsborough, J.C.; Cordy, J.; Coutts, A.J. Match-to-match variation in physical activity and technical skill measures in professional Australian Football. J. Sci. Med. Sport 2015, 18, 109-113. [CrossRef]

29. Varley, M.C.; Gabbett, T.; Aughey, R.J. Activity profiles of professional soccer, rugby league and Australian football match play. J. Sports Sci. 2013, 32, 1858-1866. [CrossRef]

30. Swann, C.; Moran, A.; Piggott, D. Defining elite athletes: Issues in the study of expert performance in sport psychology. Psychol. Sport Exerc. 2015, 16, 3-14. [CrossRef]

31. Harriss, D.J.; Atkinson, G. Ethical Standards in Sport and Exercise Science Research: 2014 Update. Int. J. Sports Med. 2013, 34, 1025-1028. [CrossRef]

32. Holme, B.R. Wearable Microsensor Technology to Measure Physical Activity Demands in Handball. Master's Thesis, Norwegian School of Sport Sciences, Oslo, Norway, 2015.

33. Rico-González, M.; Arcos, A.L.; Clemente, F.M.; Rojas-Valverde, D.; Pino-Ortega, J. Accuracy and reliability of local positioning systems for measuring sport movement patterns in stadium-scale: A systematic review. Appl. Sci. 2020, 10, 5994. [CrossRef] 
34. Johnston, R.J.; Watsford, M.L.; Kelly, S.J.; Pine, M.J.; Spurrs, R.W. Valisity and interunit reliability of 10 hz and 15 hz GPS units for assessing athlete movement demands. J. Strength Cond. Res. 2014, 28, 1649-1655. [CrossRef]

35. Luteberget, L.S.; Holme, B.R.; Spencer, M. Reliability of Wearable Inertial Measurement Units to Measure Physical Activity in Team Handball. Int. J. Sports Physiol. Perform. 2018, 13, 467-473. [CrossRef]

36. Petersen, C.; Pyne, D.; Portus, M.; Dawson, B. Validity and Reliability of GPS Units to Monitor Cricket-Specific Movement Patterns. Int. J. Sports Physiol. Perform. 2009, 4, 381-393. [CrossRef]

37. Duffield, R.; Reid, M.; Baker, J.; Spratford, W. Accuracy and reliability of GPS devices for measurement of movement patterns in confined spaces for court-based sports. J. Sci. Med. Sport 2010, 13, 523-525. [CrossRef]

38. Hoppe, M.W.; Baumgart, C.; Polglaze, T.; Freiwald, J. Validity and reliability of GPS and LPS for measuring distances covered and sprint mechanical properties in team sports. PLoS ONE 2018, 13, e0192708. [CrossRef]

39. Varley, M.C.; Fairweather, I.H.; Aughey, R.J. Validity and reliability of GPS for measuring instantaneous velocity during acceleration, deceleration, and constant motion. J. Sports Sci. 2012, 30, 121-127. [CrossRef]

40. Scott, M.T.; JScorr, T.; Kelly, V.G. The validity and reliability of global positioning systems in team sports: A brief review. J Strength Cond Res. 2016, 30, 1249-1254. [CrossRef]

41. Castellano, J.; Casamichana, D.; Calleja-González, J.; Román, J.S.; Ostojic, S.M. Reliability and Accuracy of 10 Hz GPS Devices for Short-Distance Exercise. J. Sports Sci. Med. 2011, 10, 233-234.

42. Nicolella, D.P.; Torres-Ronda, L.; Saylor, K.J.; Schelling, X. Validity and reliability of an accelerometer-based player tracking device. PLoS ONE 2018, 13, e0191823. [CrossRef]

43. Fritz, C.O.; Morris, P.E.; Richler, J.J. Effect size estimates: Current use, calculations, and interpretation. J. Exp. Psychol. Gen. 2012, 141, 2-18. [CrossRef] [PubMed]

44. Ferioli, D.; Bosio, A.; Zois, J.; La Torre, A.; Rampinini, E. Seasonal changes in physical capacities of basketball players according to competitive levels and individual responses. PLoS ONE 2020, 15, e0230558. [CrossRef]

45. Pino-Ortega, J.; Rojas-Valverde, D.; Gómez-Carmona, C.D.; Bastida-Castillo, A.; Hernández-Belmonte, A.; García-Rubio, J.; Nakamura, F.Y.; Ibáñez, S.J. Impact of Contextual Factors on External Load During a Congested-Fixture Tournament in Elite U'18 Basketball Players. Front. Psychol. 2019, 10, 1100. [CrossRef]

46. Scanlan, A.; Dascombe, B.; Reaburn, P. A comparison of the activity demands of elite and sub-elite Australian men's basketball competition. J. Sports Sci. 2011, 29, 1153-1160. [CrossRef] [PubMed]

47. Alonso, E.; Miranda, N.; Zhang, S.; Sosa, C.; Trapero, J.; Lorenzo, J.; Lorenzo, A. Peak Match Demands in Young Basketball Players: Approach and Applications. Int. J. Environ. Res. Public Health 2020, 17, 2256. [CrossRef] [PubMed]

48. Fox, J.L.; Conte, D.; Stanton, R.; McLean, B.; Scanlan, A.T. The Application of Accelerometer-Derived Moving Averages to Quantify Peak Demands in Basketball. J. Strength Cond. Res. 2020. In press. [CrossRef]

49. Sampaio, J.; McGarry, T.; Calleja-González, J.; Sáiz, S.L.J.; Del Alcázar, X.S.I.; Balciunas, M. Exploring Game Performance in the National Basketball Association Using Player Tracking Data. PLoS ONE 2015, 10, e0132894. [CrossRef] [PubMed]

50. Montgomery, P.G.; Pyne, D.B.; Minahan, C.L. The Physical and Physiological Demands of Basketball Training and Competition. Int. J. Sports Physiol. Perform. 2010, 5, 75-86. [CrossRef]

51. McInnes, S.; Carlson, J.; Jones, C.; McKenna, M.J. The physiological load imposed on basketball players during competition. J. Sports Sci. 1995, 13, 387-397. [CrossRef]

52. Bradley, P.S.; Vescovi, J.D. Velocity Thresholds for Women's Soccer Matches: Sex Specificity Dictates High-Speed-Running and Sprinting Thresholds-Female Athletes in Motion (FAiM). Int. J. Sports Physiol. Perform. 2015, 10, 112-116. [CrossRef]

53. Sekine, Y.; Hoshikawa, S.; Hirose, N. Longitudinal Age-Related Morphological and Physiological Changes in Adolescent Male Basketball Players. J. Sport Sci. 2019, 18, 751-757. 